\title{
Vagus Nerve Stimulation at the Interface of Brain-Gut Interactions
}

\author{
Bruno Bonaz, ${ }^{1,2}$ Valérie Sinniger, ${ }^{1,2}$ and Sonia Pellissier ${ }^{3}$ \\ ${ }^{1}$ Division of Hepato-Gastroenterology, Grenoble University Hospital, 38043 Grenoble Cedex 09, France \\ ${ }^{2}$ U1216, INSERM, GIN, Grenoble Institute of Neurosciences, University Grenoble Alpes, Grenoble, France \\ ${ }^{3}$ University Grenoble Alpes, University Savoie Mont Blanc, 38000 Grenoble, France \\ Correspondence: bbonaz@chu-grenoble.fr
}

The vagus nerve, a key component of the cross-communication between the gut and the brain, is a major element of homeostasis sensing the "milieu intérieur" and boosting the nervous and endocrine responses to maintain the gastrointestinal health status. This nerve has anti-inflammatory properties regulating the gut through the activation of the hypothalamic-pituitary-adrenal axis and the release of cortisol and through a vagovagal reflex, which has an anti-tumor necrosis factor (TNF) effect called the cholinergic anti-inflammatory pathway. Stimulating this nerve is an interesting tool as a nondrug therapy for the treatment of gastrointestinal diseases in which brain-gut communication is dysfunctional, such as inflammatory bowel disorders and others. This review presents the rationale of vagal gastrointestinal physiology and diseases and the most recent advances in vagus nerve stimulation. It also highlights the main issues to be addressed in the future to improve this bioelectronic therapy for gastrointestinal disorders.

$T^{1}$ he brain and the gut communicate bidirectionally through the autonomic nervous system (ANS), including (1) the parasympathetic nervous system, that is, the vagus nerve (VN) originating from the cranial parasympathetic nucleus, (2) the pelvic nerves originating from the sacral parasympathetic nucleus, (3) and the sympathetic nervous system (splanchnic nerves), and the circumventricular organs (Bonaz and Bernstein 2013). The VN, a key component of these interactions, is a mixed nerve composed of $80 \%$ and $20 \%$ of afferent and efferent fibers, respectively (Prechtl and Powley 1990). Consequently, the VN is essentially a sensory nerve that informs the brain on the state of visceral organs such as the gut. In physiological conditions, the VN is implicated in homeostasis because it senses the "milieu intérieur" of the gut through the interaction of nutrients and/or gut peptides with vagal afferents (Berthoud and Neuhuber 2000; Berthoud 2004; Ritter 2004). The information is transmitted to the nucleus tractus solitarius (NTS) in the medulla, the main entrance of the VN to the brain, in close contact with the dorsal motor nucleus of the VN (DMNV) ventrally to the NTS, the origin of vagal efferents. This creates a vagovagal loop involved in the regulation of gastrointestinal

Editors: Valentin A. Pavlov and Kevin J. Tracey

Additional Perspectives on Bioelectronic Medicine available at www.perspectivesinmedicine.org

Copyright (C) 2019 Cold Spring Harbor Laboratory Press; all rights reserved; doi: 10.1101/cshperspect.a034199

Cite this article as Cold Spring Harb Perspect Med 2019;9:a034199 
B. Bonaz et al.

motility, acid secretion, food intake, and satiety (Fig. 1) (Greenwood and Davison 1987; Berthoud 2008a). From the NTS, the VN communicates via interneuron projections with the parabrachial nucleus, locus coeruleus, paraventricular nucleus of the hypothalamus (PVH), limbic system (amygdala), and other brain nuclei of the central autonomic network (CAN) (Benarroch 1993). The CAN integrates this information and then modulates the ANS through descending projections to the DMNV, thus modulating vagal efferents, and the tractus intermediolateralis of the spinal cord at the origin of the efferent sympathetic nerves (Fig. 2) (Strack et al. 1989; Abe et al. 2017). An inflammatory reflex in which vagal afferents activate vagal efferents in response to peripheral inflammation was described by Tracey (2002) to induce anti-inflammatory properties such as an anti-tumor necrosis factor (TNF) effect. The $\mathrm{VN}$ has an anti-inflammatory effect through two pathways (Fig. 3). One is a neuroendocrine pathway involving the hypothalamic-pituitaryadrenal (HPA) axis through a vago-NTS-PVH pathway leading to the release of cortisol, an anti-inflammatory hormone (Harris 1950). The other is a neural pathway, the inflammatory reflex, involving VN efferents, that is, the cholinergic anti-inflammatory pathway (CAP) (Tracey 2007). Such anti-inflammatory properties could be used to dampen peripheral inflammation of the gut, through VN stimulation (VNS), as observed in inflammatory bowel disease (IBD), Crohn's disease (CD), and ulcerative colitis (UC), but also irritable bowel syndrome (IBS), an IBD “a minima" (Catanzaro et al. 2014). IBS and IBD are observed, respectively, in $10 \%-20 \%$ and $0.5 \%-1 \%$ of the population and are a real health cost burden. For example, $\mathrm{CD}$ and UC were associated with direct and indirect costs ranging between $\$ 14.6$ and $\$ 31.6$ billion in 2014 (Mehta 2016).

Usually, there is an equilibrium between sympathetic and parasympathetic activities referred to as the sympathovagal balance involved in homeostasis regulation. A disruption of this equilibrium favors but also reflects pathological conditions (Bonaz 2016). More specifically,

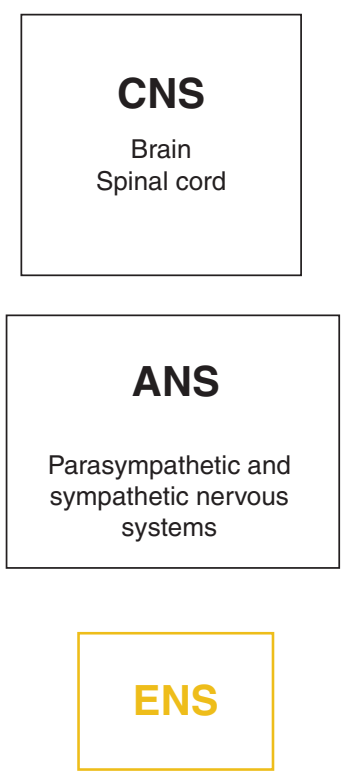

\section{Brain-gut axis}

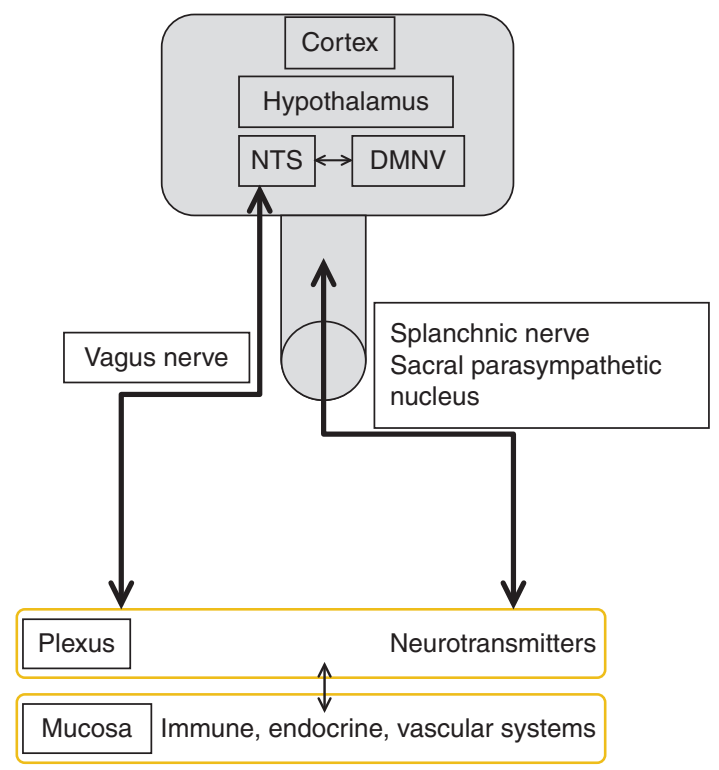

Figure 1. The brain-gut axis. The autonomic nervous system (ANS) is the bidirectional link between the central nervous system (CNS) and the gut via the enteric nervous system (ENS) and the immune, endocrine, and vascular systems. NTS, nucleus tractus solitarius; DMNV, dorsal motor nucleus of the vagus nerve. 


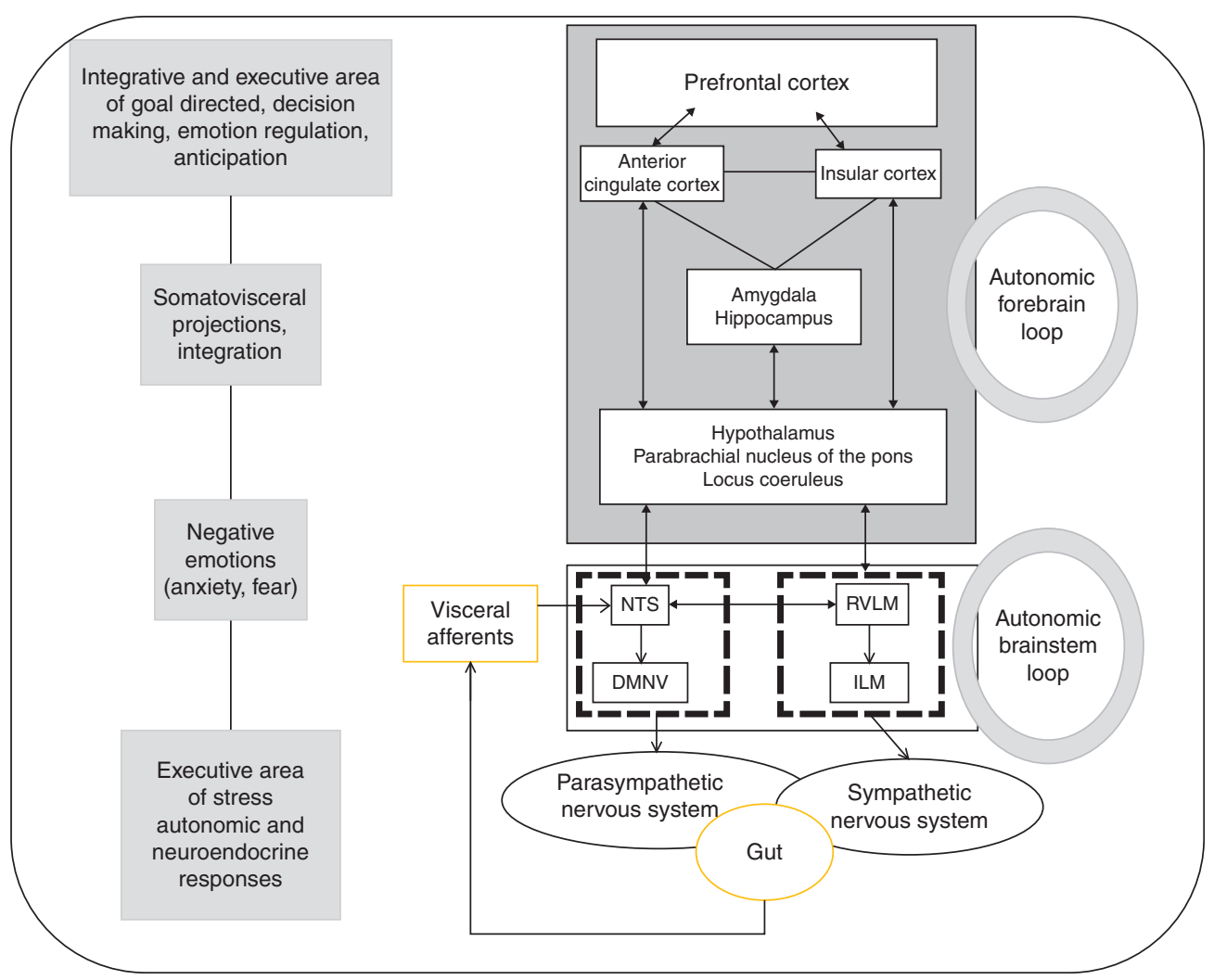

Figure 2. Brain-gut integrative pathway. The gut afferents from the vagus and splanchnic nerves are transmitted to the nucleus tractus solitarius (NTS), in the medulla in close contact with the dorsal motor nucleus of the vagus nerve (DMNV), the origin of parasympathetic vagal efferents, thus creating an autonomic brainstem loop involved in the regulation of gastrointestinal motility, acid secretion, food intake, and satiety. This loop is modulated by an autonomic forebrain loop that includes nuclei in the pons, the hypothalamus, the hippocampus, the amygdala, the anterior cingulate, the insular, and the prefrontal cortices. This forebrain loop, also referred to as the central autonomic network, coordinates visceral information in an integrative dimension that includes neuroendocrine responses, emotions, cognition, and behavior. These two central loops explain how stress, feelings, and thoughts can influence gut functioning and vice versa. RVLM, rostral ventrolateral medulla; ILM, intermediolateralis nucleus.

stress is able to induce an imbalance of the ANS and proinflammatory conditions. Stress usually stimulates the sympathetic nervous system while inhibiting the VN and stimulating the sacral parasympathetic nucleus (Tache and Bonaz 2007; Wood and Woods 2007). An imbalance of the ANS was described in IBS and IBD (Pellissier et al. 2010; Pellissier and Bonaz 2017). The variability in beat-to-beat intervals of the electrocardiogram is called heart rate variability (HRV). At rest, HRV variables are the markers of the parasympathetic vagal tone. A low HRV, marker of a low parasympathetic vagal tone, is observed in IBS and IBD and in proinflammatory conditions. Furthermore, a low HRV is associated specifically with high plasmatic levels of TNF- $\alpha$ in CD, and high resting plasmatic levels of epinephrine in IBS (Pellissier et al. 2014). Consequently, stimulating the VN to improve these diseases should be of interest.

Bioelectronic medicine is an original nondrug therapeutic approach, which relies on neuromodulation of the nervous system's electrical activity to restore organ functions and health 


\section{B. Bonaz et al.}
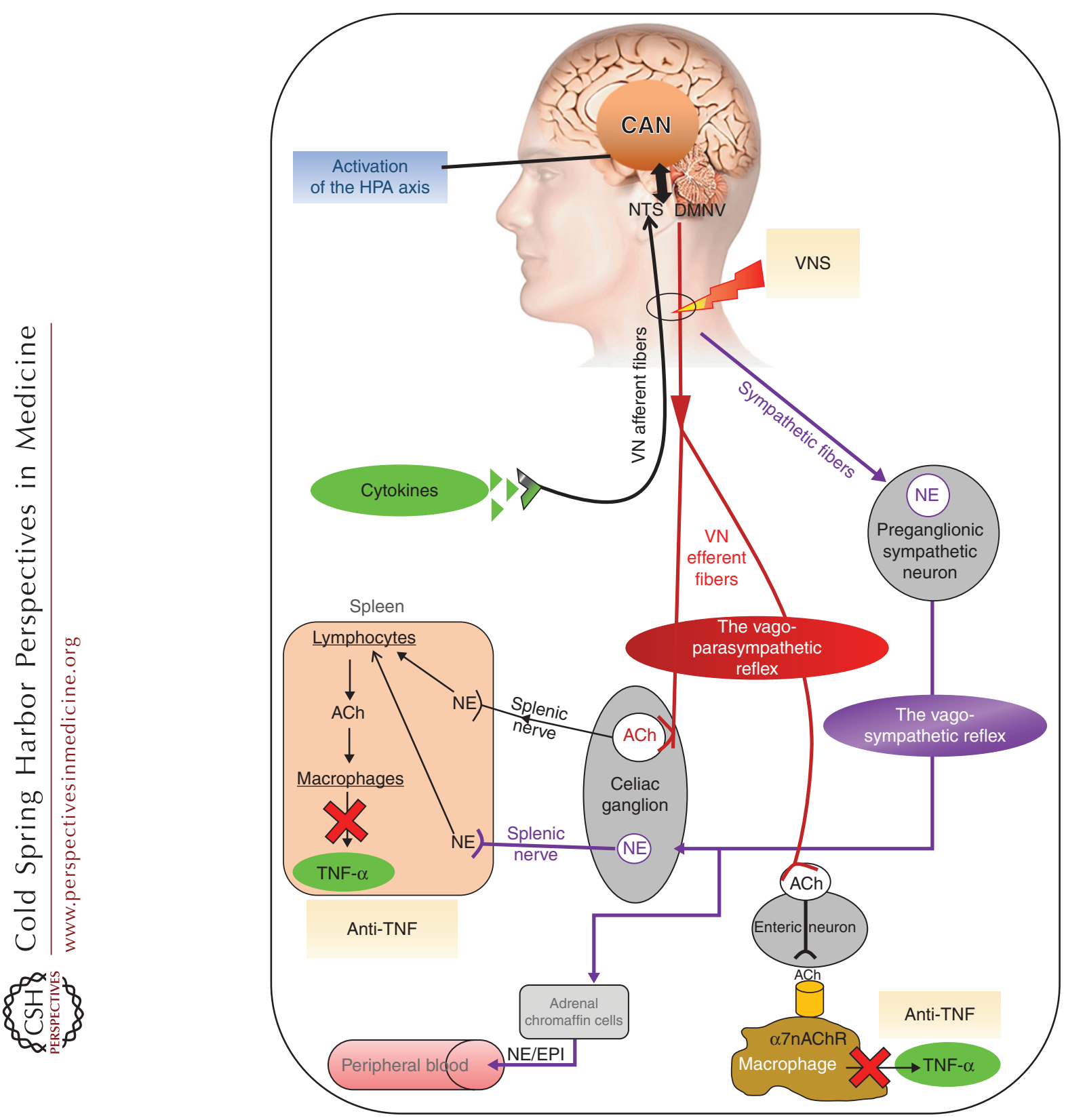

Figure 3. Different pathways of the anti-inflammatory properties of the vagus nerve and how to target the vagus nerve for its anti-inflammatory properties. ACh, acetylcholine; CAN, central autonomic network; DMNV, dorsal motor nucleus of the vagus nerve; EPI, epinephrine; HPA, hypothalamic-pituitary-adrenal; NE, norepinephrine; NTS, nucleus tractus solitarius; TNF- $\alpha$, tumor necrosis factor $\alpha$; VNS, vagus nerve stimulation; $\alpha 7 \mathrm{nAChR}$, $\alpha 7$ nicotinic acetylcholine receptor (Bonaz et al. 2017). 
without the adverse effects of pharmaceutical drugs, thus preventing compliance issues (Olofsson and Tracey 2017). Stimulating peripheral nerves, such as the VN, through VNS is of interest (Bonaz et al. 2013, 2016a,b,c, 2018). The aim of VNS is to use the anti-inflammatory properties of the $\mathrm{VN}$ and to restore a normal vagal tone. This is within the scope of bioelectronic medicine. In this article, we focus on VNS as a nondrug therapy at the interface of braingut interactions in IBD, IBS, and other inflammatory diseases.

\section{BRAIN-GUT INTERACTIONS: NEUROANATOMICAL FUNDAMENTALS}

Brain-gut interactions have been well described both at the preclinical and clinical levels. Indeed, proinflammatory cytokines are able to target circumventricular organs, which send projections to the PVH to activate the HPA axis to dampen inflammation through the release of glucocorticoids (Rivest et al. 2000). Likewise, vagal afferents distributed in the gut wall, including in the external muscle layers, myenteric plexus, and mucosal lamina propria (Fig. 4), are sensitive to distension and to the release of proinflammatory cytokines, as well as to gut peptides (CCK, GLP-1, leptin, serotonin) acting on vagal receptors and microbiota (de Lartigue and Diepenbroek 2016; Bonaz et al. 2018). The information is then transmitted to the NTS, which sends projections to the CAN inducing endocrine, autonomic, emotional, and cognitive responses (Benarroch 1993). After integrating this information, the CAN is able to modulate the efferent limbs of the ANS, that is, the VN and splanchnic nerves. In the same way, "sym-

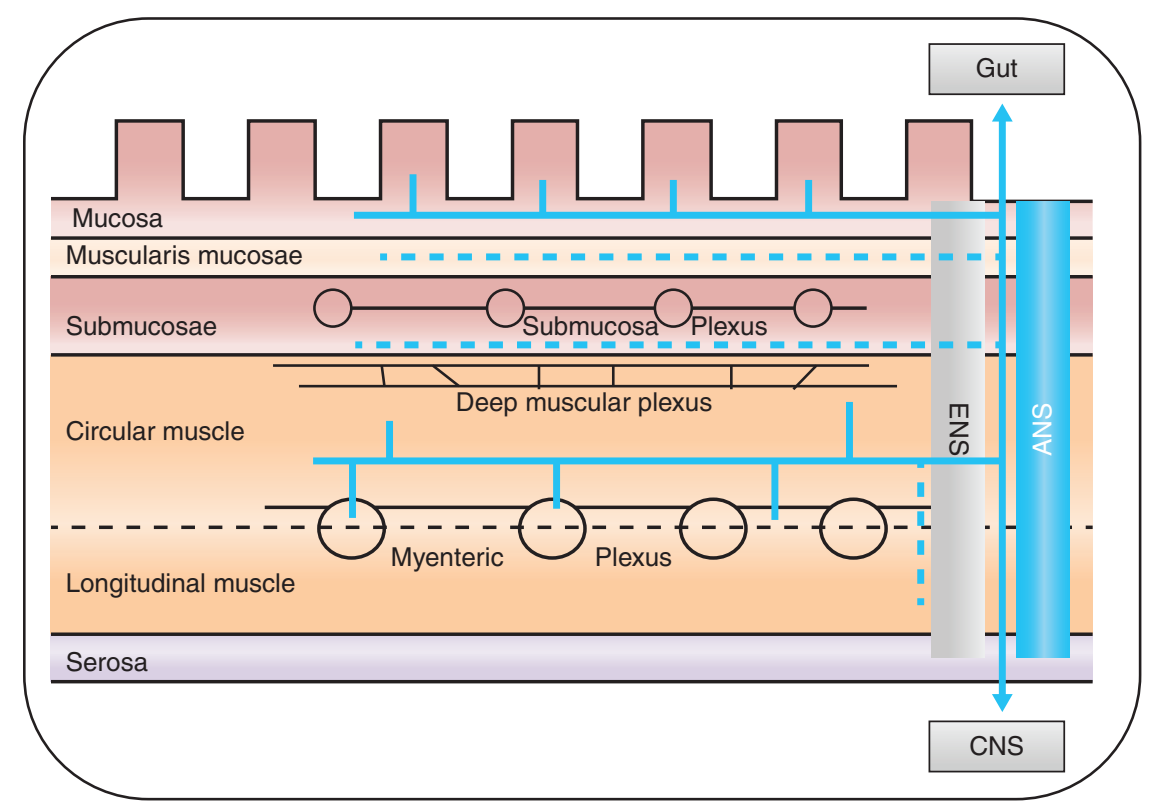

Figure 4. Extrinsic (autonomic nervous system [ANS]) and enteric nervous system (ENS) innervation of the gut. The extrinsic innervation includes the vagal parasympathetic and sympathetic systems, with afferent sensory and efferent secretomotor fibers. The ENS is a complex neural network controlling various cell populations, including smooth muscle, mucosal secretory, endocrine, and immune/inflammatory cells, as well as microvasculature (for secretion, absorption, and motility). The ENS network is organized in several plexuses, located in various levels of the gut wall, which provides a partial autonomous control of gastrointestinal functions. The ANS provides the extrinsic innervation of the gut with (1) sensory neurons linked to vagal, thoracolumbar, and lumbosacral pathways that are located at the mucosal, myenteric, muscular, and vascular levels, and (2) vagal, sacral, and sympathetic axons for motor activity. 
pathetic afferent" fibers with cell bodies localized in the dorsal root ganglia are essentially involved in visceral pain but also in gut inflammation. They project to the spinal cord and reach the NTS (Gamboa-Esteves et al. 2001) and the amygdala, through a spino-parabrachial-amygdala pathway (Bernard and Besson 1990), the thalamus, and the insula, a central locus of interoception, and then project to the anterior cingulate and prefrontal cortices (Fig. 2) (Craig 2002). Vagal and "sympathetic afferents" reach the central nervous system (CNS) through different pathways, respectively, the NTS and spinal cord; but from these locations, the brain targets are almost the same. Their common projections on insula and prefrontal cortex explain how various visceral stimuli conveyed through autonomic afferents are involved in interoception and interoceptive awareness (Craig 2002). The central sensitivity syndrome, characterizing an abnormal interoceptive process, has been described in various chronic diseases such as IBS, fibromyalgia, chronic fatigue syndrome, or posttraumatic stress disorders (Yunus 2007). All these pathways have been well identified in rodents using the expression of $c$ fos, a marker of neuronal activation (Bonaz et al. 2000; Sinniger et al. 2005) and functional human brain imaging both in physiological (Baciu et al. 1999) and pathological conditions such as IBS and IBD in which abnormal brain loci of activation, as well as abnormal morphometry, tractography, or resting state, have been described (Bernstein et al. 2002; Bonaz et al. 2002; Rubio et al. 2016; Agostini et al. 2017; Kragel et al. 2018).

There is also an anatomical link between the microbiota and the brain, that is, the microbiota-gut-brain axis in which the $\mathrm{VN}$ is involved. Indeed, the $\mathrm{VN}$ is able to sense microbiota metabolites through its afferents and to transfer this gut information to the CAN, then generating an adapted or inappropriate response from the CAN to the gut and the microbiota (Bonaz et al. 2018). The VN, via the CAP, could modulate the gut microbiota through modifications of intestinal permeability and local immunity (Bonaz et al. 2018). Thus, the vagal tone could be an interesting marker of the microbiota-gut-brain axis, and targeting vagal tone through VNS could have therapeutic implications in the modulation of this axis.

\section{ANTI-INFLAMMATORY PROPERTIES OF THE VAGUS NERVE}

As mentioned above, the VN has anti-inflammatory properties both through its afferents, (activating the HPA axis) and efferents (via the $\mathrm{CAP}$ ), putting the $\mathrm{VN}$ at the interface of the neuro-endocrine-immune axis (Bonaz et al. 2017). Tracey et al. showed, in a model of septic shock following intravenous lipopolysaccharides, that stimulating the distal end of the cut $\mathrm{VN}$, thus activating vagal efferents, was able to dampen the shock (Borovikova et al. 2000). This effect is mediated by acetylcholine (ACh), which binds to the $\alpha 7$ nicotinic cholinergic receptor ( $\alpha$ AChR) of macrophages, thus inhibiting the release of TNF- $\alpha$ by these cells (Wang et al. 2003). In the gut, the VN does not interact directly with macrophages but with nNOS-VIPACh enteric neurons (Cailotto et al. 2014). Another pathway involving the spleen has been described: an interaction of the $\mathrm{VN}$ with the splenic sympathetic nerve, which releases norepinephrine that binds to splenic T-lymphocytes $\beta 2$ receptors and leads to the inhibition of TNF- $\alpha$ release by macrophages, through an interaction of ACh with $\alpha 7 \mathrm{nAChR}$ (Fig. 3) (Rosas-Ballina et al. 2011). Some investigators have proposed alternative pathways involving the sympathetic nervous system, that is, the greater splanchnic nerves that are activated in response to an immune challenge and which, in turn, drive postganglionic sympathetic neurons to inhibit inflammation through splenic sympathetic nerve terminals (Martelli et al. 2014, 2016). Indeed, the thoracolumbar spinal cord at the origin of the splenic nerve is activated by descending pathways from $\mathrm{A} 5, \mathrm{C} 1$, and $\mathrm{PVH}$, which are connected to vagal afferents (Strack et al. 1989; Abe et al. 2017). The central cholinergic activation of a VN-to-spleen circuit has been shown to control intestinal inflammation in mice with experimental colitis by suppressing splenic immune cell activation and altered interaction between dendritic and $\mathrm{T}$ cells ( $\mathrm{Ji}$ 
et al. 2014; Munyaka et al. 2014). Furthermore, the inhibition of brain acetylcholinesterase suppresses systemic inflammation through a central muscarinic receptor-mediated and vagaland $\alpha 7 \mathrm{nAChR}$-dependent mechanism (Pavlov et al. 2009).

\section{INFLAMMATORY BOWEL DISEASE AND IRRITABLE BOWEL SYNDROME: DISORDERS OF BRAIN-GUT INTERACTIONS}

IBD and IBS are chronic disorders of the digestive tract. The symptoms described by the patients can be identical, but IBD is characterized by lesions of the digestive tract involving the rectocolon for $\mathrm{UC}$ and all the digestive tract for $\mathrm{CD}$, while the integrity of the digestive tract is preserved in IBS (Mulak and Bonaz 2004; Cosnes et al. 2011). That is why IBS is called a functional digestive disorder. However, both diseases are considered as bio-psycho-social disorders (Mulak and Bonaz 2004; Bitton et al. 2008). IBS is a disorder of brain-gut interactions but considerable data also argues for an alteration of these interactions in IBD (Bonaz and Bernstein 2013; Gracie et al. 2018). The role of stress, especially early life stress, has been shown in IBS, both in the initiation but also in the maintenance of the disease (Pellissier and Bonaz 2017), which is characterized by motility disorders, visceral hypersensitivity, perturbations of intestinal barrier, proinflammatory predisposing conditions (postinfectious and postinflammatory IBS), and dysbiosis (Holtmann et al. 2017). Stress is also involved in the pathophysiology of IBD (Bonaz and Bernstein 2013). Indeed, $\sim 50 \%$ of included patients reported significant stress in any 3-month period, but the primary types were everyday life stressors more than health-related stress (Bernstein 2010). There is strong evidence for an association between perceived stress levels and flares; and psychological factors contribute to IBD symptom flares (Bernstein et al. 2010). Stress modifies gastrointestinal motility and secretion, increases visceral sensitivity and intestinal permeability, and modifies immunity and gut blood flow; all these modifications may play a role in the path- ophysiology of IBS and IBD (Tache and Perdue 2004; Tache and Bonaz 2007; Bonaz and Bernstein 2013). Maternal deprivation in animals is an experimental model of early life trauma in humans and is commonly used as a model of brain-gut axis dysfunction (O'Mahony et al. 2011). After reaching adulthood, these animals present with visceral hypersensitivity (Moloney et al. 2012), as in IBS patients, and a worsened experimental colitis (Barreau et al. 2004). Anxiety and depression are usually observed in $\sim 30 \%-50 \%$ of IBS patients (Pellissier and Bonaz 2017). We also reported that IBD patients presented with depression even when in remission (Pellissier et al. 2010, 2014); and depressed IBD patients or patients who have inadequate coping strategies to stress are more prone to a flare of the disease (Mittermaier et al. 2004; Bitton et al. 2008). Because IBS and IBD patients have an imbalance of the ANS with a low vagal tone and an increased sympathetic tone, such conditions predispose to inflammation.

\section{VAGUS NERVE STIMULATION IN INFLAMMATORY BOWEL DISEASE}

VNS was first used in cases of drug-resistant epilepsy not amenable to resection surgery. It was validated by the Food and Drug Administration (FDA) in 1994 and for drug-resistant depression in 2005. In these indications, the aim is to target the CNS through activation of vagal afferents at high-frequency stimulation (20 to $30 \mathrm{~Hz}$ ), although even low-frequency stimulation at $5 \mathrm{~Hz}$ produces changes in brain regions, but less than at $20 \mathrm{~Hz}$ VNS (Lomarev et al. 2002). We also showed that VNS performed at a low frequency of stimulation $(5 \mathrm{~Hz})$ in rats activated the NTS and other brain regions (Reyt et al. 2010). Thus, low-frequency VNS activates both vagal afferent and efferent fibers. Although, the VNS mechanism of action is not completely understood, the locus coeruleus, thalamus, hippocampus, periaqueductal gray, and the neocortex are key components of this mechanism (Fanselow 2012).

Activation of both vagal afferents and efferents would be of interest in IBD, because of the dual anti-inflammatory role of the VN. The CAP 
B. Bonaz et al.

involves vagal efferents; thus, VNS at low frequency stimulation of these efferents should have an anti-inflammatory effect (Borovikova et al. 2000). This explains why, in an experimental study on rats presenting with TNBS colitis to mimic CD, we performed VNS at $5 \mathrm{~Hz}$ frequency stimulation during 5 consecutive days in awake animals (Meregnani et al. 2011). We showed that VNS improved colitis and this effect was predominant on tissues that were less damaged. This result was confirmed by other invesperformed a pilot study in patients with active $\mathrm{CD}$ in a translational approach. Patients were selected according to a clinical activity index (moderate-to-severe disease; $220<$ Crohn's disease activity index $[\mathrm{CDAI}]<450)$, biological pa-

rameters of inflammation such as C-reactive protein (CRP) (>5 mg/L) and/or fecal calprotectin $(>100 \mu \mathrm{g} / \mathrm{g})$, and ileocolonoscopy with an index of activity (Crohn's disease endoscopic index of severity [CDEIS], macroscopic index of mucosal healing) $\geq 7$. Patients were followed up for 1 year. We included nine patients and reported the results of this first pilot study of VNS in seven CD patients after 6 months of follow-up, giving an overview of the type of patients to be selected in a future randomized control trial (Fig. 5) (Bonaz et al. 2016a). VNS is a slow-acting therapy, as reported in epilepsy, with modifications of neuroplasticity (Biggio et al. 2009; Hays et al. 2013). Consequently, we should not include patients with severe flare-ups of the disease but only those with a mild-to-

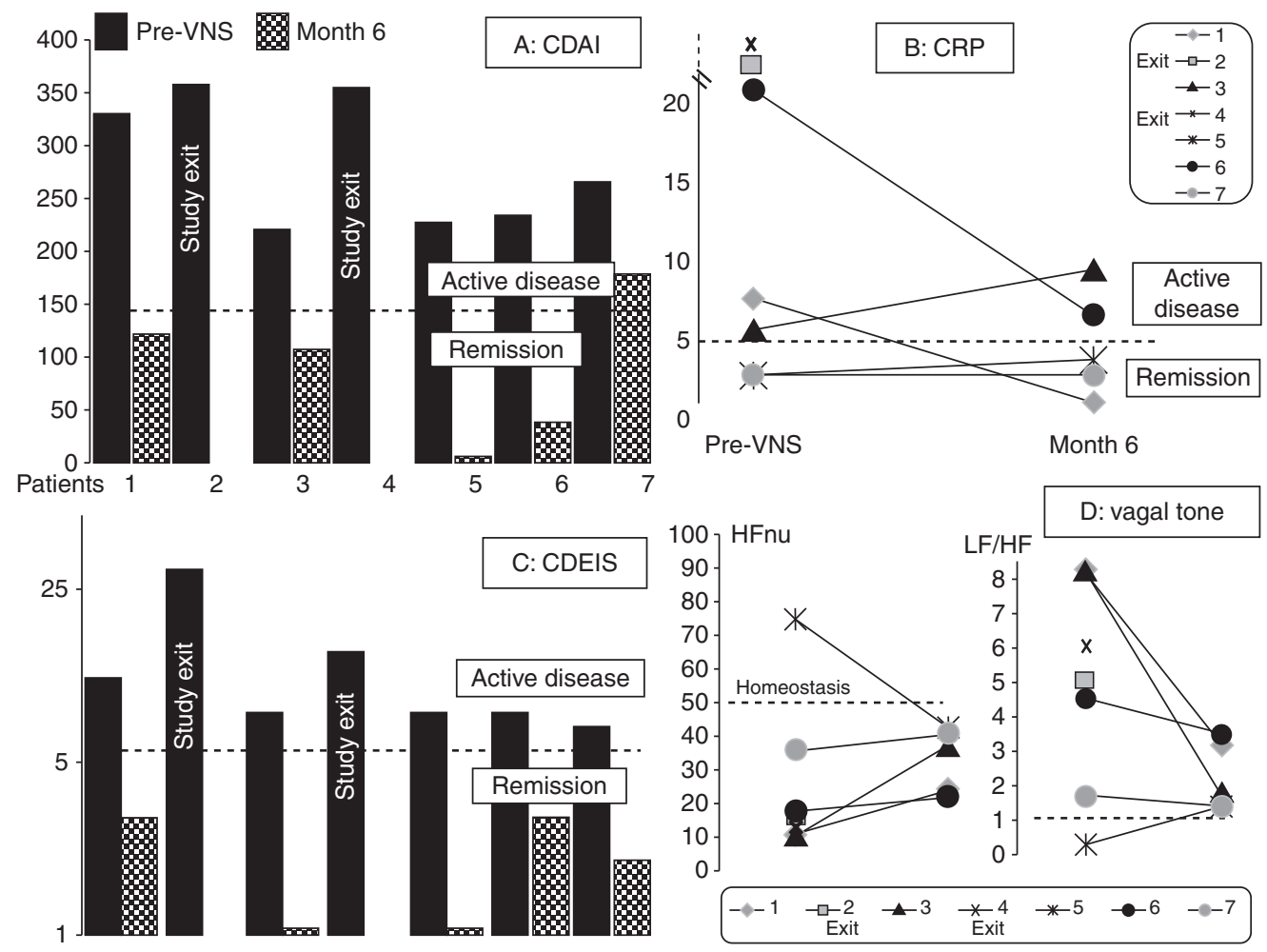

Figure 5. Effect of vagus nerve stimulation (VNS) during 6 months of follow-up in the seven patients presenting with an active Crohn's disease at inclusion on $(A)$ the Crohn's disease activity index (CDAI); $(B)$ C-reactive protein (CRP); $(C)$ the Crohn's disease endoscopic index of severity (CDEIS); $(D)$ the vagal tone (high frequency in normalized units [HFnu]) and the sympathovagal balance (low frequency [LF]/high frequency [HF]). CDAI < 150, clinical remission. Cut-off level for CRP, $5 \mathrm{mg} / \mathrm{L}$. CDEIS $<6$, endoscopic remission. HFnu, homeostatic range. Balanced ratio of LF/HF (sympathovagal balance) 1. (From Bonaz et al. 2016a; modified, with permission, from the author.) 
moderate disease. In this context, using VNS to prevent postoperative recurrence of $\mathrm{CD}$ would also be of interest. Indeed, the pathological gut is removed by surgery but this does not cure IBD, and there is usually a recurrence of $\mathrm{CD}$ at or above the anastomosis (De Cruz et al. 2012). VNS could also be used in a combination therapy with immunosuppressants or biologics (anti-TNF, anti-IL12/23, anti-integrins) to bridge the slow-acting effect of VNS and then later used as a monotherapy as reported in the first top-down study in CD in which anti-TNF (infliximab) was combined with azathioprine (D'Haens et al. 2008). Another study (G D'Haens, Z Cabrijan, M Eberhardson, et al., unpubl.) used VNS in CD patients with a history of inadequate response and/or intolerance failure to one or more anti-TNF. They also observed a clinical, biological, and endoscopic improvement in these patients. These two studies are complementary in their indications and strongly support the use of VNS in IBD treatment. Of course, a robust randomized control study versus placebo is needed in CD. VNS could also be used in patients with UC, which predominantly involves the rectocolon. The $\mathrm{VN}$ is usually considered to innervate all the digestive tract to the left splenic flexure, the rest of the colon and rectum being innervated by the pelvic nerves. But for some investigators, the $\mathrm{VN}$ innervates the entire digestive tract (Delmas and Laux 1933), thus making use of VNS compatible in UC treatment.

\section{VAGUS NERVE STIMULATION IN IRRITABLE BOWEL SYNDROME}

The $\mathrm{VN}$ is usually considered to have no effect on pain, either visceral or somatic, this effect being mediated by the sympathetic nervous system. However, experimental and clinical data showed that the VN had antinociceptive effects. Indeed, patients treated by VNS for epilepsy present with less pain (Kirchner et al. 2006). The $\mathrm{VN}$ had antinociceptive effects in experimental models of pain either somatic or visceral $(\mathrm{Zu}-$ rowski et al. 2012; Chakravarthy et al. 2016; Frokjaer et al. 2016). Because visceral hypersensitivity is a marker of IBS (Ritchie 1973), VNS would be of interest in IBS patients as an anti- nociceptive therapy. In addition, based on the fact that $\sim 30 \%$ to $50 \%$ of IBS patients present with depression (Pellissier and Bonaz 2017), the antidepressive effect of VNS would be of additional interest. There is also evidence that $\operatorname{cog}$ nition and mood improve with VNS (Chan et al. 2018). Considering that IBS is also seen as an IBD "a minima" with significant higher level of proinflammatory cytokines such as interleukin (IL)-1 $\beta$, IL-6, and TNF- $\alpha$ than controls (Liebregts et al. 2007; Bashashati et al. 2014), the anti-inflammatory effect of VNS could dampen this low-grade inflammation and alleviate pain. VNS appears as a potential therapeutic tool in IBS patients because of its anti-inflammatory, antinociceptive, and antidepressive effects. No data has been published yet regarding the use of VNS in IBS patients. However, two clinical trials using noninvasive VNS are ongoing (ClinicalTrials.gov identifiers: NCT02388269 and NCT02420158). The results are expected with interest.

\section{FUTURE OF VAGUS NERVE STIMULATION}

VNS has other potential indication in the treatment of gastrointestinal diseases, which are characterized by a dysfunction of brain-gut interactions.

\section{VNS in the Treatment of Postoperative Ileus}

Postoperative ileus (POI) is characterized by a delay of gastric emptying and prolonged intestinal transit after surgery (Stakenborg et al. 2017a). The motility of the stomach and small intestine is restored within 24 to $48 \mathrm{~h}$ and up to $72 \mathrm{~h}$ for the colon. POI can prolong hospitalization stay and increase healthcare costs estimated at U.S. $\$ 750$ million/year in the United States (Senagore 2007). Sympathoadrenergic, vagalnonadrenergic noncholinergic-inhibitory, corticotrophin-releasing pathways and capsaicinsensitive afferent neurons are involved in the mechanism of POI (Holzer et al. 1986; Barquist et al. 1996; Bonaz and Tache 1997). A peripheral pathway, involving the CAP, was also described revealing the release of TNF- $\alpha$ by resident macrophages in the muscularis propria after abdom- 


\section{B. Bonaz et al.}

inal surgery (de Jonge et al. 2003). This inflammatory response is decreased by pretreatment with selective $\alpha 7 \mathrm{nAChR}$ agonists and VNS, thus reducing macrophage activation and release of proinflammatory cytokines (The et al. 2007). The gastric POI is prevented in rats by central activation of the VN (Yuan and Tache 2017). Gum chewing, well known to activate the VN, also reduces POI (Xu et al. 2018). Hence, stimulating the CAP and its anti-inflammatory action could improve POI. Another alternative is abdominal VNS, which appears as effective as cervical VNS (Stakenborg et al. 2017b). It has the advantage of avoiding implantation of the device and an electrode used in cervical VNS.

\section{VNS in the Treatment of Obesity}

The $\mathrm{VN}$ is involved in the control of food intake and satiety (Berthoud 2008b). Gastric vagal afferents are involved in induction of satiety and proximal small intestine vagal afferents are involved in chemosensitivity-induced satiation (de Lartigue and Diepenbroek 2016). There is an intestinal lumen sensing of the VN through gastric and enteroendocrine cells (Monteiro and Batterham 2017). Vagal efferents are involved in the regulation of digestion and absorption (de Lartigue and Diepenbroek 2016). In obesity, vagal afferent signaling is disrupted, inducing an overconsumption of food and weight gain, and satiety effects of intestinal nutrients are reduced (Browning et al. 2017). Subdiaphragmatic VNS in lean animals induces weight loss, satiation, decreased food intake and sweet cravings, and increase in energy expenditure (de Lartigue and Diepenbroek 2016). Subdiaphragmatic VNS in high-fat-diet animals reduces excess weight gain, adiposity, and hyperphagia (Browning et al. 2017). Chronic VNS induces a decrease of weight gain, food consumption, and sweet cravings in adult obese mini-pigs (Val-Laillet et al. 2010).

Sixty percent of patients treated by VNS for epilepsy lost weight; patients treated with the highest frequency lost more weight (Burneo et al. 2002). In depression, weight loss was positively correlated with the initial body mass index (BMI) in patients treated by VNS for more than 2 years; the more severe the obesity, the greater the weight loss (Pardo et al. 2007). Regarding the mechanisms of VNS in obesity described above, VNS may increase the responsiveness of vagal afferent neurons to distension and/or satiating hormones. As seen above, VNS is a slow-acting therapy, suggesting that the brain adapts to VNS over time. Thus, the effectiveness of VNS in obesity may improve over time. Indeed, many studies made on rodents were 4-8 weeks long and weight loss in patients with VNS was predominantly reported after 612 months. The optimal parameters are still unclear. A frequency-dependent improvement was reported (Burneo et al. 2002). Clinical trials are ongoing on VNS for obesity (ClinicalTrial.Gov: Preoperative treatment with noninvasive intraauricular VNS pending bariatric surgery [recruiting]: NCT02648191; Study of the effect of VNS on human brown adipose tissue activity [unknown]: NCT01491282; VNS and glucose metabolism [completed]: NCT01117311). The results of these clinical trials should be of interest.

\section{VNS in Gastroparesis}

Gastroparesis is characterized by a delay of gastric emptying without any obstruction caused by an abnormal gastric contractility (Langworthy et al. 2016). The symptoms are nausea, vomiting, early satiety, abdominal pain, and bloating. Idiopathic gastroparesis, diabetes mellitus, or $\mathrm{VN}$ injury owing to gastric surgery are the main etiologies. The available treatments are rather disappointing and have a significant economic impact (Navas et al. 2017; Kumar et al. 2018). Gastric electrical stimulation with the Enterra device (Medtronic, Minneapolis, MN) is also an option for such patients (Levinthal and Bielefeldt 2017). Based on the role of the VN in nausea, gastric emptying, and nociception, VNS should be of interest. Paulon et al. (2017), in a pilot study, used noninvasive VNS in patients presenting with drug-resistant gastroparesis, with the gammaCore (electroCore, Basking Ridge, NJ) device self-administered by the patient with a 2-min stimulation of the VN at the cervical level. Patients performed two 
stimulations on each side three times daily during weeks 1 and 2 and then three stimulations on each side three times daily during week 3 and after. Thirty-five patients were enrolled, 23 (65.7\%) complied with the procedures and were included in the analysis. Seven patients continued VNS beyond 3 weeks. 8/23 (35\%) patients responded at week 3 , and 10/23 (43\%) at week 3-6. VNS was well tolerated. Improvement was observed for all the cohort and the 10 responders for nausea/vomiting, postprandial fullness/ early satiety, and bloating. This is the only published study on VNS in gastroparesis. Although underpowered, this study supports the use of VNS in the treatment of refractory gastroparesis, but this needs to be confirmed. One trial is currently ongoing (ClinicalTrials.gov identifier: NCT03120325).

\section{NONINVASIVE OR INVASIVE VNS?}

Invasive VNS was validated for epilepsy and depression. The device is usually implanted by a neurosurgeon familiar with the technique during a 1-hour surgery. There are a few adverse effects with this technique: hoarseness, throat pain, cough, and dyspnea as a result of higher stimulation settings (Cukiert 2015). If necessary, the device can be removed but the electrode wrapped around the $\mathrm{VN}$ is usually left in place, its removal being risky because of the close contact with the carotid artery and vein. Consequently, a noninvasive VNS would be of interest especially for patients reluctant to undergo surgery. The principle is to use external devices to stimulate the $\mathrm{VN}$ at the cervical level, along the carotid axis, or at the cymba concha of the external ear, which is innervated by a sensory auricular branch of the $\mathrm{VN}$ projecting to the NTS (Peuker and Filler 2002). Transcutaneous auricular VNS is thus able to stimulate the CAP through a vagovagal reflex as shown in a model of septic shock in rats (Zhao et al. 2012) and recently in healthy volunteers (Lerman et al. 2016).

Two noninvasive VNS devices are available, the NEMOS device (Cerbomed, Erlangen, Germany) relying on an intra-auricular electrode and the gammaCore device (electroCore, Bask- ing Ridge, NJ), which uses two stainless steel round discs as skin contact surfaces of the $\mathrm{VN}$ at the cervical level. They are used for epilepsy, depression, and headache (Stefan et al. 2012; Nesbitt et al. 2015; Fang et al. 2016). These devices are safe without any reported serious adverse events. No data has yet been published on the use of noninvasive VNS in inflammatory disorders of the gastrointestinal tract and only one pilot study was performed in gastroparesis (Paulon et al. 2017). The drawback of these devices could be a low compliance; 30\%-40\% of IBD patients did not follow their treatment (Herman and Kane 2015). The reproducibility of the positioning of the device either at the auricular level or at the cervical level is questionable, in particular, for the gammaCore device.

\section{QUESTIONS-FUTURE OF VNS FOR GASTROINTESTINAL DISORDERS}

Although VNS is an innovative technique for brain-gut interactions, many questions remain unanswered. Most of the studies using VNS are pilot studies with few patients included. Consequently, more robust randomized controlled trials are necessary to confirm the reported results and to convince health authorities for regulatory approval and reimbursement as well as the community of IBD (and others) physicians and patients who may be tempted by this nondrug therapeutic approach devoid of major adverse effects. Most of the studies are not controlled, thus a study on a sham-stimulated group of patients is needed with the possibility of being secondarily stimulated.

What stimulation parameters should be used? In particular, what is the optimal frequency of stimulation: high frequency as for epilepsy and depression to target the brain or low-frequency to activate vagal efferents and consequently the CAP? A dual activation of vagal afferents and efferents in a synergistic effect should be effective. Consequently, using 10 to $20 \mathrm{~Hz}$ of frequency stimulation would be of interest. The intensity ranges between 0.25 and 1.5 , usually starting at $0.25 \mathrm{~mA}$ with a step-bystep increase to the intensity tolerated by the patient without throat pain, which was, in our 
study, not more than $1.5 \mathrm{~mA}$ (Bonaz et al. 2016a). In their POI study, Stakenborg et al. (2017b) used a high intensity ( $2.5 \mathrm{~mA})$ of stimulation in patients that were under anesthesia for abdominal surgery; but, at the level of cervical VNS, such an intensity would most likely not be tolerated by the patients.

What is the optimal duration of stimulation? We used $30 \mathrm{sec}$ ON and $5 \mathrm{~min}$ OFF, as for epilepsy and depression, but Levine et al. (2014) reported that VNS delivered once daily for 60 sec inhibited cytokine production and induced significant protection against synovitis and periarticular bone erosions. In the same way, Koopman et al. (2016) used intermittent VNS in rheumatoid arthritis (RA) patients during 60 sec up to four times daily. Stakenborg et al. (2017b) used 2 min of VNS at the beginning and at the end of surgery.

Helmers et al. (2012) reported that, based on a computational model, a range of output current settings between 0.75 and $1.75 \mathrm{~mA}$ with pulse width settings of 250 or $500 \mu$ s could result in optimal stimulation. The miniaturization of the VNS device is required. The Setpoint company elaborated on a device that directly stimulates the VN by clipping it around the VN (see setpointmedical.com; MØ1-ØØ1123), thus avoiding a subclavicular incision to position the neurostimulator. The neurostimulator evolved in the domain of epilepsy. The AspireSR can detect the ictal tachycardia as a proxy to an epileptic seizure and deliver a closed-loop electrical current to the VN. Hamilton et al. (2018) recently reported that $\sim 70 \%$ of patients treated with an implanted VNS device presented with significant additional benefit. In the same way, it would be interesting to have a device able to measure HRV to assess vagal tone and to stimulate the $\mathrm{VN}$ in the case of a long-lasting low vagal tone according to body characteristics (temperature, movements, sleep cycles, inflammatory markers) so as to restore a normal tone.

The efficacy of VNS is most likely influenced by morphometric parameters of the VN but very little data is available. The $\mathrm{VN}$ is not completely encircled by the electrode because it is wrapped around it for $\sim 270^{\circ}$. Nerve fibers not covered by the electrode should require higher stimulation, whereas fibers located near the perineurium of a fascicle are exposed to a stronger electric field (Helmers et al. 2012). The right cervical VN has a 1.5 times larger effective surface area than the left cervical and there is a large variation within individual nerves (Verlinden et al. 2016). The mean effective surface area at the right cervical level is greater than at the level inside the skull base, implying that the $\mathrm{VN}$ receives anastomosing branches from areas other than the brainstem. Tyrosine hydroxylase- and dopamine $\beta$-hydroxylase-nerve fibers have been individualized in the $\mathrm{VN}$, indicating a catecholaminergic neurotransmission.

More recently, Hammer et al. (2018) investigated the detailed morphometry, vascularity, and surface topography of the cervical VN for both invasive and noninvasive VNS. They did not find any sex-, side,- or branching-related differences. An electrode diameter of $7.5 \mathrm{~mm}$ would suit most patients. It was highly unlikely to find the nerve below $50 \mathrm{~mm}$ of the surface and the laryngeal eminence. The number of vagal arteries in the sample of this study was much smaller than reported previously; $49 \%$ were confirmed in this case by histology.

All these technical points should be taken into consideration when developing clinical trials on VNS in gastrointestinal diseases (and others) because they may influence the results of these studies.

It is currently difficult to predict which patients will respond to VNS therapy for the gastrointestinal tract and to what extent; although, in epilepsy, Liu et al. (2018) recently reported that preoperative assessment of HRV could help in predicting VNS outcomes in patients with drug-resistant epilepsy. Patients responding to VNS had less impairment of parasympathetic cardiac control than nonresponders. In our pilot study in $\mathrm{CD}$, patients with a low HRV responded to VNS.

\section{CONCLUSION}

VNS is an interesting nondrug therapy in the treatment of gastrointestinal diseases, which are related to brain-gut disorders such as IBD, IBS, and others. Robust randomized control tri- 
als are still necessary to confirm this because only pilot studies are available at this time.

\section{ACKNOWLEDGMENTS}

Our work is supported by the National Institute for Health and Medical Research (INSERM) and Ministry of Health, France (DGOS) (“Appel à Projet Translationnel 2011”) and the Grenoble Hospital Department of Clinical Research and Innovation (DRCI), France. The authors thank (1) Mr. Nicolas Gonnet, Mr. David Tartry, and Mrs. Mélanie Arnaud (Clinical Research Associates) for their help in the management of our clinical trial on vagus nerve stimulation in patients with Crohn's disease, (2) Mrs. Françoise Bardin who helped with the formatting of the manuscript, and (3) Dr. Pierre-Emmanuel Colle for copy-editing the article.

\section{REFERENCES}

Abe C, Inoue T, Inglis MA, Viar KE, Huang L, Ye H, Rosin DL, Stornetta RL, Okusa MD, Guyenet PG. 2017. C1 neurons mediate a stress-induced anti-inflammatory reflex in mice. Nat Neurosci 20: 700-707.

Agostini A, Ballotta D, Righi S, Moretti M, Bertani A, Scarcelli A, Sartini A, Ercolani M, Nichelli P, Campieri M, et al. 2017. Stress and brain functional changes in patients with Crohn's disease: A functional magnetic resonance imaging study. Neurogastroenterol Motil 29: 1-10.

Baciu MV, Bonaz BL, Papillon E, Bost RA, Le Bas JF, Fournet J, Segebarth CM. 1999. Central processing of rectal pain: A functional MR imaging study. AJNR Am J Neuroradiol 20: $1920-1924$.

Barquist E, Bonaz B, Martinez V, Rivier J, Zinner MJ, Tache Y. 1996. Neuronal pathways involved in abdominal surgery-induced gastric ileus in rats. Am J Physiol 270: R888R894.

Barreau F, Ferrier L, Fioramonti J, Bueno L. 2004. Neonatal maternal deprivation triggers long term alterations in colonic epithelial barrier and mucosal immunity in rats. Gut 53: 501-506.

Bashashati M, Rezaei N, Shafieyoun A, McKernan DP, Chang L, Ohman L, Quigley EM, Schmulson M, Sharkey KA, Simren M. 2014. Cytokine imbalance in irritable bowel syndrome: A systematic review and meta-analysis. Neurogastroenterol Motil 26: 1036-1048.

Benarroch EE. 1993. The central autonomic network: Functional organization, dysfunction, and perspective. Mayo Clin Proc 68: 988-1001.

Bernard JF, Besson JM. 1990. The spino(trigemino)pontoamygdaloid pathway: Electrophysiological evidence for an involvement in pain processes. J Neurophysiol 63: 473-490.
Bernstein CN. 2010. New insights into IBD epidemiology: Are there any lessons for treatment? Dig Dis 28: 406-410.

Bernstein CN, Frankenstein UN, Rawsthorne P, Pitz M, Summers R, McIntyre MC. 2002. Cortical mapping of visceral pain in patients with GI disorders using functional magnetic resonance imaging. Am J Gastroenterol 97: 319-327.

Bernstein CN, Singh S, Graff LA, Walker JR, Miller N, Cheang M. 2010. A prospective population-based study of triggers of symptomatic flares in IBD. Am J Gastroenterol 105: 1994-2002.

Berthoud HR. 2004. Neural control of appetite: Cross-talk between homeostatic and non-homeostatic systems. Appetite 43: 315-317.

Berthoud HR. 2008a. Vagal and hormonal gut-brain communication: From satiation to satisfaction. Neurogastroenterol Motil 20: 64-72.

Berthoud HR. 2008b. The vagus nerve, food intake and obesity. Regul Pept 149: 15-25.

Berthoud HR, Neuhuber WL. 2000. Functional and chemical anatomy of the afferent vagal system. Auton Neurosci 85: $1-17$.

Biggio F, Gorini G, Utzeri C, Olla P, Marrosu F, Mocchetti I, Follesa P. 2009. Chronic vagus nerve stimulation induces neuronal plasticity in the rat hippocampus. Int J Neuropsychopharmacol 12: 1209-1221.

Bitton A, Dobkin PL, Edwardes MD, Sewitch MJ, Meddings JB, Rawal S, Cohen A, Vermeire S, Dufresne L, Franchimont D, et al. 2008. Predicting relapse in Crohn's disease: A biopsychosocial model. Gut 57: 1386-1392.

Bonaz B. 2016. Autonomic dysfunction: A predictive factor of risk to develop rheumatoid arthritis? EBioMedicine 6: 20-21.

Bonaz BL, Bernstein CN. 2013. Brain-gut interactions in inflammatory bowel disease. Gastroenterology 144: 3649.

Bonaz B, Tache Y. 1997. Corticotropin-releasing factor and systemic capsaicin-sensitive afferents are involved in abdominal surgery-induced Fos expression in the paraventricular nucleus of the hypothalamus. Brain Res 748: 12 20.

Bonaz B, Riviere PJ, Sinniger V, Pascaud X, Junien JL, Fournet J, Feuerstein C. 2000. Fedotozine, a $\kappa$-opioid agonist, prevents spinal and supra-spinal Fos expression induced by a noxious visceral stimulus in the rat. Neurogastroenterol Motil 12: 135-147.

Bonaz B, Baciu M, Papillon E, Bost R, Gueddah N, Le Bas JF, Fournet J, Segebarth C. 2002. Central processing of rectal pain in patients with irritable bowel syndrome: An fMRI study. Am J Gastroenterol 97: 654-661.

Bonaz B, Picq C, Sinniger V, Mayol JF, Clarencon D. 2013. Vagus nerve stimulation: From epilepsy to the cholinergic anti-inflammatory pathway. Neurogastroenterol Motil 25: 208-221.

Bonaz B, Sinniger V, Hoffmann D, Clarencon D, Mathieu N, Dantzer C, Vercueil L, Picq C, Trocme C, Faure P, et al. 2016a. Chronic vagus nerve stimulation in Crohn's disease: A 6-month follow-up pilot study. Neurogastroenterol Motil 28: 948-953.

Bonaz B, Sinniger V, Pellissier S. 2016b. Anti-inflammatory properties of the vagus nerve: Potential therapeutic im- 
B. Bonaz et al.

plications of vagus nerve stimulation. J Physiol 594: 57815790.

Bonaz B, Sinniger V, Pellissier S. 2016c. Vagal tone: Effects on sensitivity, motility, and inflammation. Neurogastroenterol Motil 28: 455-462.

Bonaz B, Sinniger V, Pellissier S. 2017. The vagus nerve in the neuro-immune axis: Implications in the pathology of the gastrointestinal tract. Front Immunol 8: 1452.

Bonaz B, Bazin T, Pellissier S. 2018. The vagus nerve at the interface of the microbiota-gut-brain axis. Front Neurosci 12: 49.

Borovikova LV, Ivanova S, Zhang M, Yang H, Botchkina GI, Watkins LR, Wang H, Abumrad N, Eaton JW, Tracey KJ. 2000. Vagus nerve stimulation attenuates the systemic inflammatory response to endotoxin. Nature 405: 458462.

Browning KN, Verheijden S, Boeckxstaens GE. 2017. The vagus nerve in appetite regulation, mood, and intestinal inflammation. Gastroenterology 152: 730-744.

Burneo JG, Faught E, Knowlton R, Morawetz R, Kuzniecky R. 2002. Weight loss associated with vagus nerve stimulation. Neurology 59: 463-464.

Cailotto C, Gomez-Pinilla PJ, Costes LM, van der Vliet J, Di Giovangiulio M, Nemethova A, Matteoli G, Boeckxstaens GE. 2014. Neuro-anatomical evidence indicating indirect modulation of macrophages by vagal efferents in the intestine but not in the spleen. PLOS ONE 9: e87785.

Catanzaro R, Occhipinti S, Calabrese F, Anzalone MG, Milazzo M, Italia A, Marotta F. 2014. Irritable bowel syndrome: New findings in pathophysiological and therapeutic field. Minerva Gastroenterol Dietol 60: 151-163.

Chakravarthy K, Nava A, Christo PJ, Williams K. 2016. Review of recent advances in peripheral nerve stimulation (PNS). Curr Pain Headache Rep 20: 60.

Chan AY, Rolston JD, Rao VR, Chang EF. 2018. Effect of neurostimulation on cognition and mood in refractory epilepsy. Epilepsia Open 3: 18-29.

Cosnes J, Gower-Rousseau C, Seksik P, Cortot A. 2011. Epidemiology and natural history of inflammatory bowel diseases. Gastroenterology 140: 1785-1794.

Craig AD. 2002. How do you feel? Interoception: The sense of the physiological condition of the body. Nat Rev Neurosci 3: 655-666.

Cukiert A. 2015. Vagus nerve stimulation for epilepsy: An evidence-based approach. Prog Neurol Surg 29: 39-52.

De Cruz P, Kamm MA, Prideaux L, Allen PB, Desmond PV. 2012. Postoperative recurrent luminal Crohn's disease: A systematic review. Inflamm Bowel Dis 18: 758-777.

de Jonge WJ, van den Wijngaard RM, The FO, ter Beek ML, Bennink RJ, Tytgat GN, Buijs RM, Reitsma PH, van Deventer SJ, Boeckxstaens GE. 2003. Postoperative ileus is maintained by intestinal immune infiltrates that activate inhibitory neural pathways in mice. Gastroenterology 125: 1137-1147.

de Lartigue G, Diepenbroek C. 2016. Novel developments in vagal afferent nutrient sensing and its role in energy homeostasis. Curr Opin Pharmacol 31: 38-43.

Delmas J, Laux G. 1933. Anatomie médico-chirurgicale du système nerveux végétatif: (sympathique \& parasympathique). Masson, Paris.
D’Haens GR, Vermeire S, Van Assche G, Noman M, Aerden I, Van Olmen G, Rutgeerts P. 2008. Therapy of metronidazole with azathioprine to prevent postoperative recurrence of Crohn's disease: A controlled randomized trial. Gastroenterology 135: 1123-1129.

Fang J, Rong P, Hong Y, Fan Y, Liu J, Wang H, Zhang G, Chen X, Shi S, Wang L, et al. 2016. Transcutaneous vagus nerve stimulation modulates default mode network in major depressive disorder. Biol Psychiatry 79: 266-273.

Fanselow EE. 2012. Central mechanisms of cranial nerve stimulation for epilepsy. Surg Neurol Int 3: S247-S254.

Frokjaer JB, Bergmann S, Brock C, Madzak A, Farmer AD, Ellrich J, Drewes AM. 2016. Modulation of vagal tone enhances gastroduodenal motility and reduces somatic pain sensitivity. Neurogastroenterol Motil 28: 592-598.

Gamboa-Esteves FO, Tavares I, Almeida A, Batten TF, McWilliam PN, Lima D. 2001. Projection sites of superficial and deep spinal dorsal horn cells in the nucleus tractus solitarii of the rat. Brain Res 921: 195-205.

Gracie DJ, Guthrie EA, Hamlin PJ, Ford AC. 2018. Bi-directionality of brain-gut interactions in patients with inflammatory bowel disease. Gastroenterology 154: 16351646.e3.

Greenwood B, Davison JS. 1987. The relationship between gastrointestinal motility and secretion. Am J Physiol 252: G1-G7.

Hamilton P, Soryal I, Dhahri P, Wimalachandra W, Leat A, Hughes D, Toghill N, Hodson J, Sawlani V, Hayton T, et al. 2018. Clinical outcomes of VNS therapy with AspireSR (including cardiac-based seizure detection) at a large complex epilepsy and surgery centre. Seizure 58: 120-126.

Hammer N, Loffler S, Cakmak YO, Ondruschka B, Planitzer U, Schultz M, Winkler D, Weise D. 2018. Cervical vagus nerve morphometry and vascularity in the context of nerve stimulation-A cadaveric study. Sci Rep 8: 7997.

Harris GW. 1950. The hypothalamus and endocrine glands. Br Med Bull 6: 345-350.

Hays SA, Rennaker RL, Kilgard MP. 2013. Targeting plasticity with vagus nerve stimulation to treat neurological disease. Prog Brain Res 207: 275-299.

Helmers SL, Begnaud J, Cowley A, Corwin HM, Edwards JC, Holder DL, Kostov H, Larsson PG, Levisohn PM, De Menezes MS, et al. 2012. Application of a computational model of vagus nerve stimulation. Acta Neurol Scand 126: 336-343.

Herman ML, Kane SV. 2015. Treatment nonadherence in inflammatory bowel disease: Identification, scope, and management strategies. Inflamm Bowel Dis 21: 29792984.

Holtmann G, Shah A, Morrison M. 2017. Pathophysiology of functional gastrointestinal disorders: A holistic overview. Dig Dis 35: 5-13.

Holzer P, Lippe IT, Holzer-Petsche U. 1986. Inhibition of gastrointestinal transit due to surgical trauma or peritoneal irritation is reduced in capsaicin-treated rats. Gastroenterology 91: 360-363.

Ji H, Rabbi MF, Labis B, Pavlov VA, Tracey KJ, Ghia JE. 2014. Central cholinergic activation of a vagus nerve-to-spleen circuit alleviates experimental colitis. Mucosal Immunol 7: 335-347. 
Jin H, Guo J, Liu J, Lyu B, Foreman RD, Yin J, Shi Z, Chen JDZ. 2017. Anti-inflammatory effects and mechanisms of vagal nerve stimulation combined with electroacupuncture in a rodent model of TNBS-induced colitis. Am Physiol Gastrointest Liver Physiol 313: G192-G202.

Kirchner A, Stefan H, Bastian K, Birklein F. 2006. Vagus nerve stimulation suppresses pain but has limited effects on neurogenic inflammation in humans. Eur J Pain 10: $449-455$.

Koopman FA, Chavan SS, Miljko S, Grazio S, Sokolovic S, Schuurman PR, Mehta AD, Levine YA, Faltys M, Zitnik $\mathrm{R}$, et al. 2016. Vagus nerve stimulation inhibits cytokine production and attenuates disease severity in rheumatoid arthritis. Proc Natl Acad Sci 113: 8284-8289.

Kragel PA, Kano M, Van Oudenhove L, Ly HG, Dupont P, Rubio A, Delon-Martin C, Bonaz BL, Manuck SB, Gianaros PJ, et al. 2018. Generalizable representations of pain, cognitive control, and negative emotion in medial frontal cortex. Nat Neurosci 21: 283-289.

Kumar M, Chapman A, Javed S, Alam U, Malik RA, Azmi S. 2018. The investigation and treatment of diabetic gastroparesis. Clin Ther 40: 850-861.

Langworthy J, Parkman HP, Schey R. 2016. Emerging strategies for the treatment of gastroparesis. Expert Rev Gastroenterol Hepatol 10: 817-825.

Lerman I, Hauger R, Sorkin L, Proudfoot J, Davis B, Huang A, Lam K, Simon B, Baker DG. 2016. Noninvasive transcutaneous vagus nerve stimulation decreases whole blood culture-derived cytokines and chemokines: A randomized, blinded, healthy control pilot trial. Neuromodulation 19: 283-290.

Levine YA, Koopman FA, Faltys M, Caravaca A, Bendele A, Zitnik R, Vervoordeldonk MJ, Tak PP. 2014. Neurostimulation of the cholinergic anti-inflammatory pathway ameliorates disease in rat collagen-induced arthritis. PLoS ONE 9: e104530.

Levinthal DJ, Bielefeldt K. 2017. Systematic review and metaanalysis: Gastric electrical stimulation for gastroparesis. Auton Neurosci 202: 45-55.

Liebregts T, Adam B, Bredack C, Roth A, Heinzel S, Lester S, Downie-Doyle S, Smith E, Drew P, Talley NJ, et al. 2007. Immune activation in patients with irritable bowel syndrome. Gastroenterology 132: 913-920.

Liu HY, Yang Z, Meng FG, Guan YG, Ma YS, Liang SL, Lin JL, Pan LS, Zhao MM, Qu W, et al. 2018. Preoperative heart rate variability as predictors of vagus nerve stimulation outcome in patients with drug-resistant epilepsy. Sci Rep 8: 3856.

Lomarev M, Denslow S, Nahas Z, Chae JH, George MS, Bohning DE. 2002. Vagus nerve stimulation (VNS) synchronized BOLD fMRI suggests that VNS in depressed adults has frequency/dose dependent effects. J Psychiatr Res 36: 219-227.

Martelli D, McKinley MJ, McAllen RM. 2014. The cholinergic anti-inflammatory pathway: A critical review. Auton Neurosci 182: 65-69.

Martelli D, Farmer DG, Yao ST. 2016. The splanchnic antiinflammatory pathway: Could it be the efferent arm of the inflammatory reflex? Exp Physiol 101: 1245-1252.

Mehta F. 2016. Report: Economic implications of inflammatory bowel disease and its management. Am J Manag Care 22: s51-s60.
Meregnani J, Clarencon D, Vivier M, Peinnequin A, Mouret C, Sinniger V, Picq C, Job A, Canini F, Jacquier-Sarlin M, et al. 2011. Anti-inflammatory effect of vagus nerve stimulation in a rat model of inflammatory bowel disease. Auton Neurosci 160: 82-89.

Mittermaier C, Dejaco C, Waldhoer T, Oefferlbauer-Ernst A, Miehsler W, Beier M, Tillinger W, Gangl A, Moser G. 2004. Impact of depressive mood on relapse in patients with inflammatory bowel disease: A prospective 18month follow-up study. Psychosom Med 66: 79-84.

Moloney RD, O'Leary OF, Felice D, Bettler B, Dinan TG, Cryan JF. 2012. Early-life stress induces visceral hypersensitivity in mice. Neurosci Lett 512: 99-102.

Monteiro MP, Batterham RL. 2017. The importance of the gastrointestinal tract in controlling food intake and regulating energy balance. Gastroenterology 152: 1707-1717. e2.

Mulak A, Bonaz B. 2004. Irritable bowel syndrome: A model of the brain-gut interactions. Med Sci Monit 10: RA55RA62.

Munyaka P, Rabbi MF, Pavlov VA, Tracey KJ, Khafipour E, Ghia JE. 2014. Central muscarinic cholinergic activation alters interaction between splenic dendritic cell and $\mathrm{CD} 4^{+} \mathrm{CD} 2^{-} \mathrm{T}$ cells in experimental colitis. PLoS ONE 9: e109272.

Navas CM, Patel NK, Lacy BE. 2017. Gastroparesis: Medical and therapeutic advances. Dig Dis Sci 62: 2231-2240.

Nesbitt AD, Marin JC, Tompkins E, Ruttledge MH, Goadsby PJ. 2015. Initial use of a novel noninvasive vagus nerve stimulator for cluster headache treatment. Neurology 84: 1249-1253.

Olofsson PS, Tracey KJ. 2017. Bioelectronic medicine: Technology targeting molecular mechanisms for therapy. $J$ Intern Med 282: 3-4.

O’Mahony SM, Hyland NP, Dinan TG, Cryan JF. 2011. Maternal separation as a model of brain-gut axis dysfunction. Psychopharmacology (Berl) 214: 71-88.

Pardo JV, Sheikh SA, Kuskowski MA, Surerus-Johnson C Hagen MC, Lee JT, Rittberg BR, Adson DE. 2007. Weight loss during chronic, cervical vagus nerve stimulation in depressed patients with obesity: An observation. Int $J$ Obes (Lond) 31: 1756-1759.

Paulon E, Nastou D, Jaboli F, Marin J, Liebler E, Epstein O. 2017. Proof of concept: Short-term non-invasive cervical vagus nerve stimulation in patients with drug-refractory gastroparesis. Frontline Gastroenterol 8: 325-330.

Pavlov VA, Parrish WR, Rosas-Ballina M, Ochani M, Puerta M, Ochani K, Chavan S, Al-Abed Y, Tracey KJ. 2009. Brain acetylcholinesterase activity controls systemic cytokine levels through the cholinergic anti-inflammatory pathway. Brain Behav Immun 23: 41-45.

Pellissier S, Bonaz B. 2017. The place of stress and emotions in the irritable bowel syndrome. Vitam Horm 103: 327354.

Pellissier S, Dantzer C, Canini F, Mathieu N, Bonaz B. 2010. Psychological adjustment and autonomic disturbances in inflammatory bowel diseases and irritable bowel syndrome. Psychoneuroendocrinology 35: 653-662.

Pellissier S, Dantzer C, Mondillon L, Trocme C, Gauchez AS, Ducros V, Mathieu N, Toussaint B, Fournier A, Canini F, et al. 2014. Relationship between vagal tone, cortisol, 
B. Bonaz et al.

TNF- $\alpha$, epinephrine and negative affects in Crohn's disease and irritable bowel syndrome. PLOS ONE 9: e105328.

Peuker ET, Filler TJ. 2002. The nerve supply of the human auricle. Clin Anat 15: 35-37.

Prechtl JC, Powley TL. 1990. The fiber composition of the abdominal vagus of the rat. Anat Embryol (Berl) 181: 101-115.

Reyt S, Picq C, Sinniger V, Clarencon D, Bonaz B, David O. 2010. Dynamic causal modelling and physiological confounds: A functional MRI study of vagus nerve stimulation. Neuroimage 52: 1456-1464.

Ritchie JA. 1973. The irritable colon syndrome-An unhappy coincidence? Tijdschr Gastroenterol 16: 243-253.

Ritter RC. 2004. Increased food intake and CCK receptor antagonists: Beyond abdominal vagal afferents. Am J Physiol Regul Integr Comp Physiol 286: R991-R993.

Rivest S, Lacroix S, Vallieres L, Nadeau S, Zhang J, Laflamme N. 2000. How the blood talks to the brain parenchyma and the paraventricular nucleus of the hypothalamus during systemic inflammatory and infectious stimuli. Proc Soc Exp Biol Med 223: 22-38.

Rosas-Ballina M, Olofsson PS, Ochani M, Valdes-Ferrer SI, Levine YA, Reardon C, Tusche MW, Pavlov VA, Andersson U, Chavan S, et al. 2011. Acetylcholine-synthesizing T cells relay neural signals in a vagus nerve circuit. Science 334: 98-101.

Rubio A, Pellissier S, Van Oudenhove L, Ly HG, Dupont P, Tack J, Dantzer C, Delon-Martin C, Bonaz B. 2016. Brain responses to uncertainty about upcoming rectal discomfort in quiescent Crohn's disease-An fMRI study. Neurogastroenterol Motil 28: 1419-1432.

Senagore AJ. 2007. Pathogenesis and clinical and economic consequences of postoperative ileus. Am J Health Syst Pharm 64: S3-S7.

Sinniger V, Mouchet P, Bonaz B. 2005. Effect of nor-trimebutine on neuronal activation induced by a noxious stimulus or an acute colonic inflammation in the rat. Life Sci 77: 2927-2941.

Stakenborg N, Gomez-Pinilla PJ, Boeckxstaens GE. 2017a. Postoperative ileus: Pathophysiology, current therapeutic approaches. Handb Exp Pharmacol 239: 39-57.

Stakenborg N, Wolthuis AM, Gomez-Pinilla PJ, Farro G, Di Giovangiulio M, Bosmans G, Labeeuw E, Verhaegen M, Depoortere I, D'Hoore A, et al. 2017b. Abdominal vagus nerve stimulation as a new therapeutic approach to prevent postoperative ileus. Neurogastroenterol Motil 29: e13075.

Stefan H, Kreiselmeyer G, Kerling F, Kurzbuch K, Rauch C, Heers M, Kasper BS, Hammen T, Rzonsa M, Pauli E, et al. 2012. Transcutaneous vagus nerve stimulation (t-VNS) in pharmacoresistant epilepsies: A proof of concept trial. Epilepsia 53: e115-e118.

Strack AM, Sawyer WB, Platt KB, Loewy AD. 1989. CNS cell groups regulating the sympathetic outflow to adrenal gland as revealed by transneuronal cell body labeling with pseudorabies virus. Brain Res 491: 274-296.
Sun P, Zhou K, Wang S, Li P, Chen S, Lin G, Zhao Y, Wang T. 2013. Involvement of MAPK/NF- $\kappa B$ signaling in the activation of the cholinergic anti-inflammatory pathway in experimental colitis by chronic vagus nerve stimulation. PLoS ONE 8: e69424.

Tache Y, Bonaz B. 2007. Corticotropin-releasing factor receptors and stress-related alterations of gut motor function. J Clin Invest 117: 33-40.

Tache Y, Perdue MH. 2004. Role of peripheral CRF signalling pathways in stress-related alterations of gut motility and mucosal function. Neurogastroenterol Motil 16: 137142.

The FO, Boeckxstaens GE, Snoek SA, Cash JL, Bennink R, Larosa GJ, van den Wijngaard RM, Greaves DR, de Jonge WJ. 2007. Activation of the cholinergic anti-inflammatory pathway ameliorates postoperative ileus in mice. Gastroenterology 133: 1219-1228.

Tracey KJ. 2002. The inflammatory reflex. Nature 420: $853-$ 859.

Tracey KJ. 2007. Physiology and immunology of the cholinergic antiinflammatory pathway. J Clin Invest 117: 289296.

Val-Laillet D, Biraben A, Randuineau G, Malbert CH. 2010. Chronic vagus nerve stimulation decreased weight gain, food consumption and sweet craving in adult obese minipigs. Appetite 55: 245-252.

Verlinden TJ, Rijkers K, Hoogland G, Herrler A. 2016. Morphology of the human cervical vagus nerve: Implications for vagus nerve stimulation treatment. Acta Neurol Scand 133: 173-182.

Wang H, Yu M, Ochani M, Amella CA, Tanovic M, Susarla S, Li JH, Wang H, Yang H, Ulloa L, et al. 2003. Nicotinic acetylcholine receptor $\alpha 7$ subunit is an essential regulator of inflammation. Nature 421: 384-388.

Wood SK, Woods JH. 2007. Corticotropin-releasing factor receptor-1: A therapeutic target for cardiac autonomic disturbances. Expert Opin Ther Targets 11: 1401-1413.

Xu C, Peng J, Liu S, Qi DY. 2018. Effect of chewing gum on gastrointestinal function after gynecological surgery: A systematic literature review and meta-analysis. J Obstet Gynaecol Res 44: 936-943.

Yuan PQ, Tache Y. 2017. Abdominal surgery induced gastric ileus and activation of M1-like macrophages in the gastric myenteric plexus: Prevention by central vagal activation in rats. Am J Physiol Gastrointest Liver Physiol 313: G320G329.

Yunus MB. 2007. Fibromyalgia and overlapping disorders: The unifying concept of central sensitivity syndromes. Semin Arthritis Rheum 36: 339-356.

Zhao YX, He W, Jing XH, Liu JL, Rong PJ, Ben H, Liu K, Zhu B. 2012. Transcutaneous auricular vagus nerve stimulation protects endotoxemic rat from lipopolysaccharideinduced inflammation. Evid Based Complement Alternat Med 2012: 627023.

Zurowski D, Nowak L, Wordliczek J, Dobrogowski J, Thor PJ. 2012. Effects of vagus nerve stimulation in visceral pain model. Folia Med Cracov 52: 57-69. 


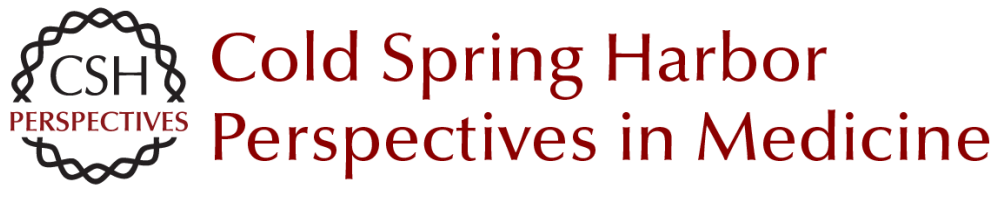

\title{
Vagus Nerve Stimulation at the Interface of Brain-Gut Interactions
}

\author{
Bruno Bonaz, Valérie Sinniger and Sonia Pellissier \\ Cold Spring Harb Perspect Med 2019; doi: 10.1101/cshperspect.a034199 originally published online \\ September 10, 2018
}

\section{Subject Collection Bioelectronic Medicine}

Neural Control of Inflammation: Bioelectronic Medicine in Treatment of Chronic Inflammatory

Disease

Michael Eberhardson, Laura Tarnawski, Monica

Centa, et al.

Noninvasive Neuromodulation of Peripheral Nerve

Pathways Using Ultrasound and Its Current

Therapeutic Implications

Christopher Puleo and Victoria Cotero

Enteric Neuromodulation for the Gut and Beyond

Yogi A. Patel and Pankaj J. Pasricha

\section{Optogenetic Control of the Peripheral Nervous} System

Rui B. Chang

Closed-Loop Neuromodulation in Physiological and Translational Research Stavros Zanos

Electrical Impedance Methods in Neuromuscular Assessment: An Overview

Seward B. Rutkove and Benjamin Sanchez

Optogenetic Medicine: Synthetic Therapeutic

Solutions Precision-Guided by Light Haifeng Ye and Martin Fussenegger

Technobiology's Enabler: The Magnetoelectric Nanoparticle

Sakhrat Khizroev
Bioelectronic Medicine: From Preclinical Studies on the Inflammatory Reflex to New Approaches in Disease Diagnosis and Treatment

Valentin A. Pavlov, Sangeeta S. Chavan and Kevin J. Tracey

Vagus Nerve Stimulation and the Cardiovascular System

Michael J. Capilupi, Samantha M. Kerath and Lance B. Becker

Harnessing the Inflammatory Reflex for the Treatment of Inflammation-Mediated Diseases Yaakov A. Levine, Michael Faltys and David Chernoff

Recording and Decoding of Vagal Neural Signals Related to Changes in Physiological Parameters and Biomarkers of Disease

Theodoros P. Zanos

Restoring Movement in Paralysis with a

Bioelectronic Neural Bypass Approach: Current

State and Future Directions Chad E. Bouton

Bioelectronic Medicine--Ethical Concerns Samuel Packer, Nicholas Mercado and Anita Haridat

Use of Bioelectronics in the Gastrointestinal Tract Larry Miller, Aydin Farajidavar and Anil Vegesna

Vagus Nerve Stimulation at the Interface of BrainGut Interactions

Bruno Bonaz, Valérie Sinniger and Sonia Pellissier

For additional articles in this collection, see http://perspectivesinmedicine.cshlp.org/cgi/collection/ 